\title{
Sternal reconstruction using locking compression plates (LCP): our experience in Egypt, a case series
}

Kareem Ahmed $^{1 *}$ and Mohamed Alaa Nady ${ }^{2}$

\begin{abstract}
Background: Sternal fractures are rare accounting for about 3-8\% of traumatic chest. There are many lines of treatments for sternal fractures which can be classified as conservative or surgical. Surgical techniques include wire fixation and sternal plating. There are no standardization of indications for each line of management. We explore if sternal reconstruction using locking titanium plates and self-tapping screws provide the patient with the best chance of proper sternal healing avoiding chronic pain and its complications and allow the patient early mobilization and rapid restoring of his normal life at its maximum.
\end{abstract}

Methods: Our inclusion criteria are patients of both gender from 20 to 60 years of age presented with traumatic sternal fracture at any site or pathological fracture due to metastatic or primary tumors infiltrating the sternum. High Associated Injury Scale scores were excluded. Exclusion criteria also included patients younger than 20 years or older than 60 years. Primary outcome is post-operative pain score and is measured using numerical pain scale ranging from zero to 10 where zero means there is no pain at all and ten is the worst imaginable pain ever.

Results: Sternal reconstruction using titanium plates has proven to be an efficient method of stabilization with tremendous immediate relief of pain showed by the differences between pre-operative and post-operative pain scale scores in our patients $(n=5)$ with Median scores being 7 and 1.5 with range being from 7 to 9 and 1 to 3 respectively ( $p$-value $=.039$ ). Operative time range between $150 \mathrm{~min}$ and $90 \mathrm{~min}$ with median of $120 \mathrm{~min}$. Extubation of patients was smooth with no events with median time of extubation being 120 min. From our experience, there were no observed wound complications except at the third patient who suffered a small wound hematoma that was resolved by gentle compressing only and needed no further intervention.

Conclusion: We recommend adopting sternal reconstruction using titanium plating systems more readily encouraging even larger clinical trials on the way to a clear guidelines. Plating systems show promising results with least pain, better stability, less complications and rapid, smooth recovery.

Trial registration: NCT04092374

Keywords: Sternum, Fracture, Reconstruction, Titanium, Plates, Screws, Pain

\footnotetext{
* Correspondence: kareemdna94@gmail.com

${ }^{1}$ Cardiothoracic Surgery Department, Assiut University Heart Hospital, Assiut, Egypt

Full list of author information is available at the end of the article
}

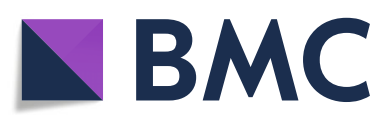

(- The Author(s). 2020 Open Access This article is licensed under a Creative Commons Attribution 4.0 International License, which permits use, sharing, adaptation, distribution and reproduction in any medium or format, as long as you give appropriate credit to the original author(s) and the source, provide a link to the Creative Commons licence, and indicate if changes were made. The images or other third party material in this article are included in the article's Creative Commons licence, unless indicated otherwise in a credit line to the material. If material is not included in the article's Creative Commons licence and your intended use is not permitted by statutory regulation or exceeds the permitted use, you will need to obtain permission directly from the copyright holder. To view a copy of this licence, visit http://creativecommons.org/licenses/by/4.0/. The Creative Commons Public Domain Dedication waiver (http://creativecommons.org/publicdomain/zero/1.0/) applies to the data made available in this article, unless otherwise stated in a credit line to the data. 


\section{Background}

Sternal fractures are rare accounting for about $3-8 \%$ of traumatic chest injuries $[1,2]$. It needs high velocity trauma especially common with deceleration accidents. There are many lines of treatments for sternal fractures which can be classified as conservative or surgical. Surgical techniques include wire fixation and sternal plating. There are no standardization of indications for each line of management [2].

We explore if sternal reconstruction using locking titanium plates and self-tapping screws provide the patient with the best chance of proper sternal healing avoiding chronic pain and its complications and allow the patient early mobilization and rapid restoring of his normal life at its maximum especially for those patients who depend on active lifestyle.

\section{Methods}

This is a case series of patients who needed sternal reconstruction for traumatic and pathological causes. Our inclusion criteria are patients of both gender from 20 to 60 years of age presented with traumatic sternal fracture at any site or pathological fracture due to metastatic or primary tumors infiltrating the sternum. High Associated Injury Scale scores were excluded due to affection on our primary outcome acting as a confounder. Exclusion criteria also included patients younger than 20 years or older than 60 years. Primary outcome is post-operative pain score and is measured using numerical pain scale ranging from zero to 10 where zero means there is no pain at all and ten is the worst imaginable pain ever. Our secondary outcomes include hospital stay and period of bed recumbence. Sternal fracture is defined as discontinuity of sternal cortex at any part of the cortex palpated on examination and seen by imaging techniques such as CXR and CT chest. Planning is done based on prior assessment of patients' general condition, their preferences and a written consent is signed. Choosing type and shape of plates is made based on site of fracture and mechanics of movement at this part to provide the most achievable stability. End state variables will be designated, such as, morbidity, or mortality. Morbidity will include wound infection, postoperative pain, delayed healing, sternal dehiscence \& postoperative length of hospital stay at short term post-operative period. Analysis of post-operative pain will be done using numerical pain score system. Post-Operative sternal healing will be assessed by the standard suitable imaging modality, MSCT Chest with 3D Reconstruction is used in all casesWound healing will be assessed by close monitoring for signs of inflammation or infections such as redness, increasing pain, wound discharge or swelling.

Titanium plates were used with different shapes and sizes according to site of fracture from BIOMET $^{\mathrm{Tw}}$ with $2.4 \% 8 \mathrm{~mm}$ self-tapping screw.

\section{Results}

First case

Male patient 45 years old, presented to trauma department with motor vehicle accident (MVA), general condition was good with GCS 14, vitally stable. Examination showed bruising on chest with tenderness over upper chest. Primary survey showed suspicious appearance at manubrium at CXR so we proceeded with MSCT chest for further evaluation and it showed fracture of manubrium together with left sterno-clavicular joint fracture and no other abnormalities were detected. Planning for surgery is done after counselling the patient. We used 4-holes straight titanium plate for manubrial fracture and 4-holes orbital titanium plate with titanium $2.7 \mathrm{~mm}$ auto self-tapping screws for further stabilization at manubrio-sternal joint. Post-operative pain score was 1 compared with 7 preoperatively $\{P$-value (.034) $\}$ with early recovery and ambulation. Hospital stay was 2 days including the day of surgery. Early Post-operative follow-up showed excellent wound healing with no seroma nor surgical site infection (Figs. 1 and 2).

\section{Second case}

Male patient, 50 years old presented to trauma department with blunt trauma to chest because of motor vehicle accident. Patient was vitally stable, GCS 15 with agonizing pain. Appropriate analgesia is administrated together with primary survey which showed mid-sternal fracture at lateral CXR and no other abnormalities could be detected. MSCT chest was obtained for further evaluation of the fracture. It showed mid-sternal fracture. Counselling of the patient with planning for surgery is made. One orbital titanium plate is used for fixation of the fracture. Post-operative pain score was 1. Hospital

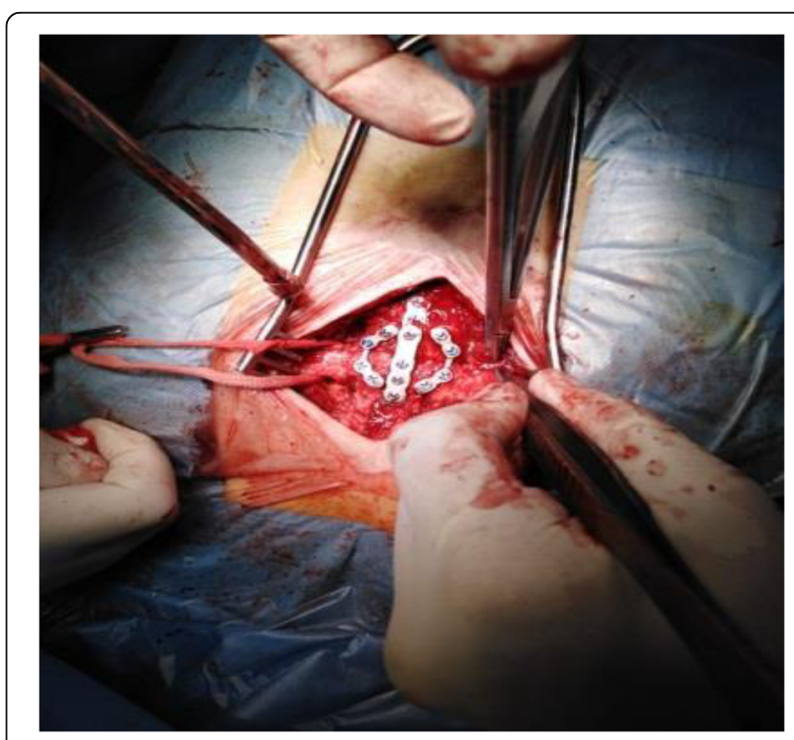

Fig. 1 Intra-operative Plates in situ 


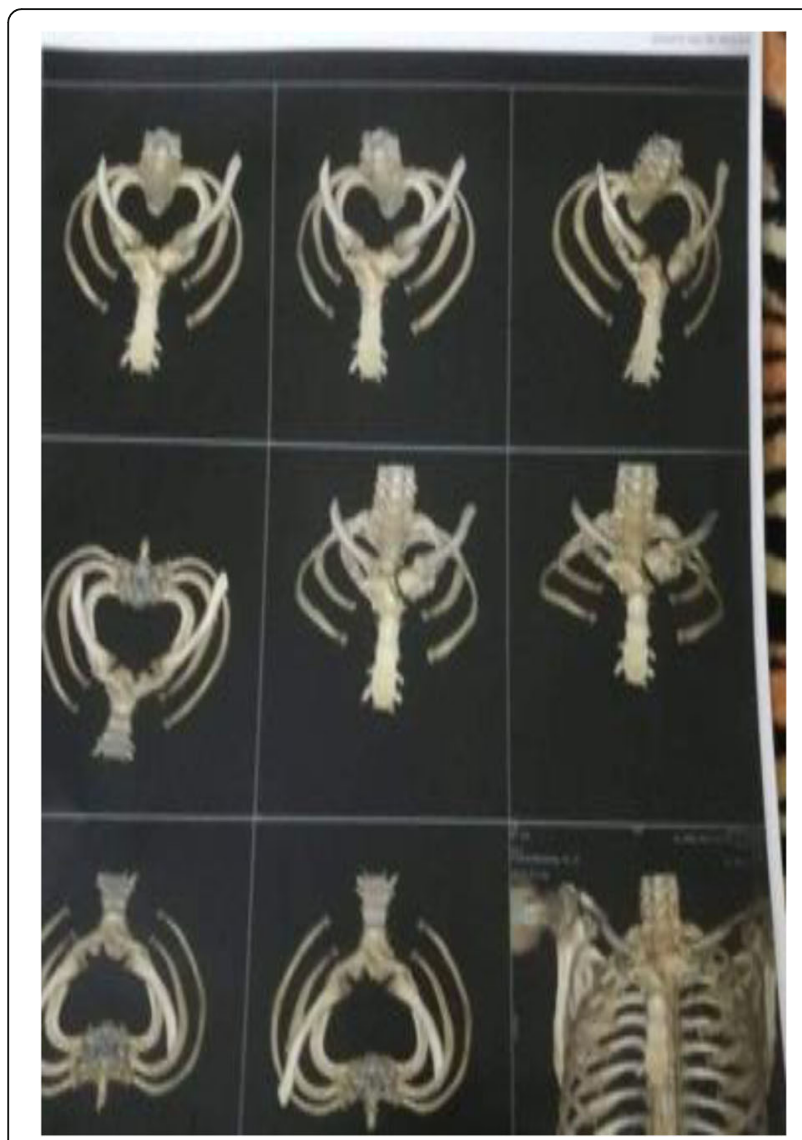

Fig. 2 Pre-operative MSCT chest showing fractures sites

stay was 2 days with early mobility and rapid recovery without any respiratory function complications.

\section{Third case}

Male patient, 45 years presented to our trauma department with motor vehicle accident, GCS could not be assessed due to motor system affection. Patient presented vitally stable with $\mathrm{BP} 110 / 70, \mathrm{HR} 85, \mathrm{SaO} 2$ on Room air (RA) 97\%. Primary survey showed abnormal sternal appearance on CXR together right radial fracture. MSCT chest showed manubrio-sternal joint fracture with mild lung contusion. MSCT spine showed cervical injury and patient needed collar for stabilization of cervical spine. Patient was unable to move both his legs and showed sensory level affection starting at $\mathrm{T} 10$ dermatome (umbilicus). His right forearm was put in plaster of Pairs (POP) after orthopedics evaluation. Counselling of patient is done about options of fixation of his sternal fracture and planning for plate fixation is made after his choice and consenting. Although this patient has high associated injury scale (AIS) score, we were concerning about providing our patient with best options for better coping and faster recovery from his sternal fracture which was adding sever pain to his suffering. We used straight titanium plate with two orbital plates at each side for better stability of his sternum and pain recovery. His pain score was not reliable due to other confounding factors which are cervical agonizing pain and his sensory level loss. However, he showed excellent recovery postoperatively in the form of good wound healing, normal respiratory function tests without any deterioration which gives us a clue about stability and recovery of his sternum that caused no further pain which if persisted could lead to chest stitching pain with respiration leading to decrease inspiratory reserve volume, atelectasis and suppression of cough mechanisms with chest infections super-imposed. Hospital stay was 40 days due to orthopedics and neurosurgery follow-up (Figs. 3, 4 and 5).

\section{Fourth case}

Male patient, 55 years, presented with blunt trauma to his chest of high velocity. Primary survey of the patient showed no abnormalities. Sever tenderness on his chest raised our suspicious so we proceeded with MSCT chest. It showed fracture at his manubrium. We used $\mathrm{H}$ shaped titanium plate. His Pain score was 2. His hospital stay was 4 days (Fig. 6).

\section{Fifth case}

Male patient, 42 years old, was diagnosed with chondrosarcoma at the body of the tumor. MSCT chest is done for staging and evaluation of the patient alluding its suitability for excision. After discussion with patient and consenting, surgical excision was the decision. At exploration the mass had infiltrated the whole body of the sternum and overlying pectoral muscle. Surgical excision of the body of the sternum together with the overlying pectoralis is done leaving a big gap. Titanium mesh $20 * 10 \mathrm{~cm}$ is used fixed by

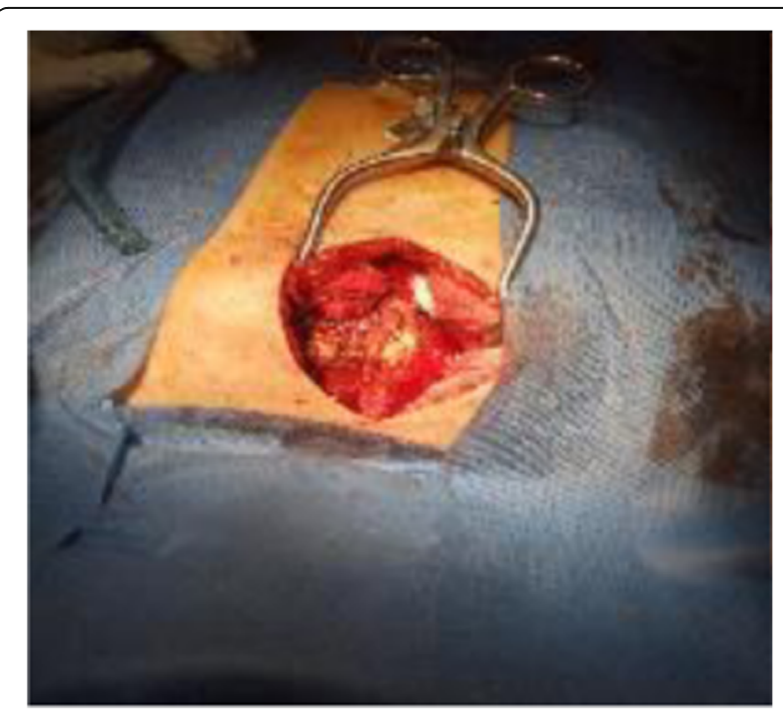

Fig. 3 Preoperative photo showing fracture at manubrio-sternal joint 


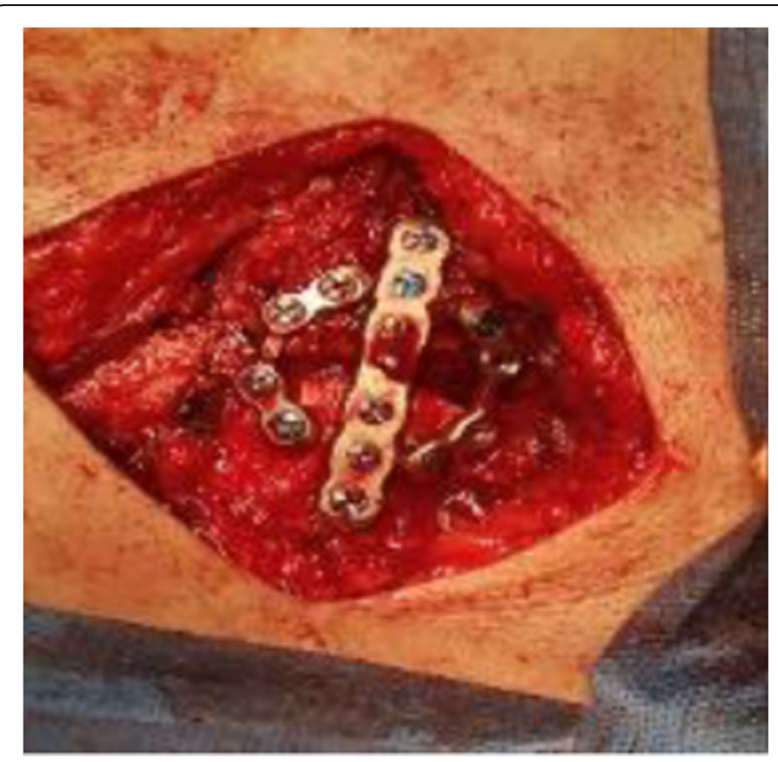

Fig. 4 Intraoperative fixation of sternal fracture by one straight and 2 orbital titanium plates

$2 \mathrm{~mm}$ titanium screws and sandwiched between 2 layers of prolene meshes. Post-operative pain score was 2 at third day and he was discharged successfully at that day with good recovery. At 1 week post-operative follow-up, there has been good stability of chest wall with perfect wound healing (Table 1).

\section{Discussion}

Sternal reconstruction using titanium plates has proven to be an efficient method of stabilization with tremendous immediate relief of pain showed by the differences between pre-operative and post-operative pain scale scores in our patients $(n=5)$ with Median scores being 7 and 1.5 with

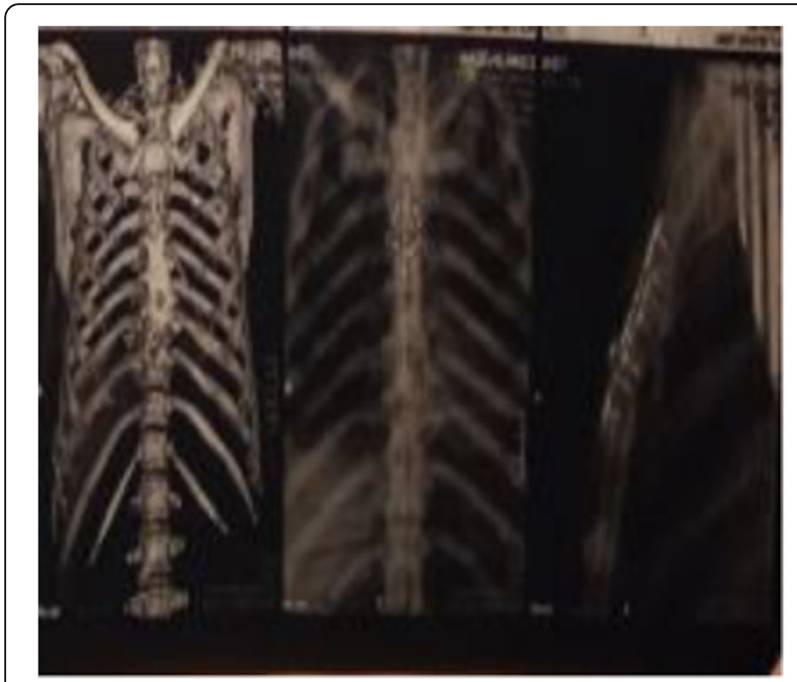

Fig. 5 Postoperative MSCT chest showing Titanium plates in position

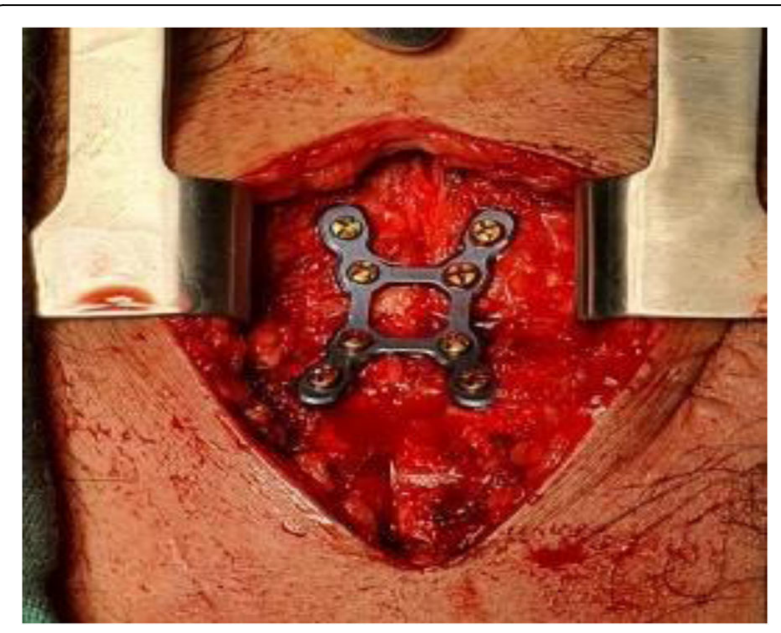

Fig. 6 Intraoperative H-shaped plate in position

range being from 7 to 9 and 1 to 3 respectively ( $p$-value $=$ .039). Operative time range between $150 \mathrm{~min}$ and $90 \mathrm{~min}$ with median of $120 \mathrm{~min}$. Extubation of patients was smooth with no events with median time of extubation being $120 \mathrm{~min}$. From our experience, there were no observed wound complications except at the third patient who suffered a small wound hematoma that was resolved by gentle compressing only and needed no further intervention. Indeed, wound seroma or hematoma was reported in many literature with a rate of $24 \%$ of cases [3, 4] and there were no relations between its incidence and using plating systems [4, 5]. Instead, It can be better explained by hemostasis issues or pectoral vessels minors bleeds [6] Bleeding was reported and is most probably due to intercostal vessels injury [7]. This might have higher incidence with transverse plates and reckless drilling or inappropriate length of screws. However, this should be least likely to occur with longitudinal plates [8]. We recommend cautious evaluation of the depth of drilling and length of the screws to be used. Post-operative analgesia for all our patients is ibuprofen tabs $400 \mathrm{mg}$ PO twice daily for 5 days. Prior to extubation and after transfer from OR to ICU, ketorolac $30 \mathrm{mg}$ IV bolus is given to all our patients once.

Plating stabilization of sternum shows mechanical superiority over other methods of stabilization taking into consideration the liability of this part of chest wall to motion with spontaneous ventilation and minor movement being an important point of muscle and ribs attachment and the complex mechanics of chest wall. Trivial movements are making shear forces which disrupt healing process needing absolute stability necessitating good stabilization $[9,10]$. This gives plating technique the advantage of providing better and faster sternal healing keeping respiratory functions unaffected with normal chest wall motion avoiding atelectasis and chest infections resulting from severe pain affecting respiration $[11,12]$. 
Table 1 Table shows summary of different variables of our represented cases with means of values

\begin{tabular}{|c|c|c|c|c|c|c|}
\hline & Case 1 & Case 2 & Case 3 & Case 4 & Case 5 & Median \\
\hline Age (years) & 45 & 50 & 45 & 55 & 42 & 45 \\
\hline Pain Score (Post-Operative) & 1 & 1 & Unreliable $^{a}$ & 2 & 2 & 1.5 \\
\hline Operative Time (minutes) & 120 & 100 & 90 & 130 & 150 & 120 \\
\hline Ex-tubation (minutes) & 120 & 120 & 60 & 120 & 120 & 120 \\
\hline Hospital Stay (Days) & 2 & 2 & $40^{\mathrm{b}}$ & 3 & 2 & $N \backslash A^{b}$ \\
\hline
\end{tabular}

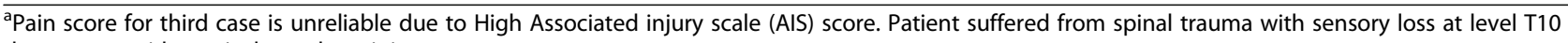
dermatome with cervical vertebrae injury

${ }^{b}$ Increased length of hospital stay is due to associated injuries

Small number of cases [13-15] presented in our work hinder us incapable of giving a strict recommendations yet we think that our results are promising and sharing such results with the international scientific community will help encouraging more surgeons to explore this new technique. We are hoping that our upcoming work will be presented with more cases enough to reach clear guidelines on using plating technique for sternal reconstruction.

\section{Conclusion}

We recommend exploring sternal reconstruction using titanium plating systems more readily encouraging even larger studies on the way to a clear guidelines. Giving our patients the best available curative options for sternal reconstruction with better Quality of Adjusted Life Years (QALY) should be our main consideration. Plating systems show promising results with least pain, better stability, less complications and rapid, smooth recovery.

\section{Abbreviations}

LCP: Locking Compression Plates; NSAIDs: Non-Steroidal Anti-Inflammatory Drugs; CXR: chest X-Rays; MSCT: Multi Slice Computed Tomography; POP: Plaster Of Paris; GCS: Glasgow Coma Scale; QAYL: Quality of Adjusted Years of Life; AIS: Associated Injury Scale

\section{Acknowledgements}

Not applicable.

\section{Authors' contributions}

Authors share equal contribution to this work. The author(s) read and approved the final manuscript.

\section{Funding}

Not applicable.

\section{Availability of data and materials}

The datasets used and/or analyzed during the current study are available from the corresponding author on reasonable request.

\section{Ethics approval and consent to participate}

All patients were consented before any intervention. The study is approved by Faculty Of Medicine, Assiut University Ethical Committee.

\section{Consent for publication}

All patents have signed consent to publish. However, no personal data that may reveal identity of the patients were shared.

\section{Competing interests}

The authors declare that they have no competing interests.

\section{Author details}

${ }^{1}$ Cardiothoracic Surgery Department, Assiut University Heart Hospital, Assiut, Egypt. ${ }^{2}$ Cardiothoracic Surgery, Assiut University Heart Hospital, Assiut, Egypt.

Received: 10 June 2020 Accepted: 10 August 2020

Published online: 21 August 2020

\section{References}

1. Demondion P, Mercier O, Kolb F, Fadel E. Sternal replacement with a custom-made titanium plate after resection of a solitary breast cancer metastasis. Interact Cardiovasc Thorac Surg. 2014;18(1):145-7.

2. Divisi D, Di Leonardo G, Crisci R. Surgical management of traumatic isolated sternal fracture and manubriosternal dislocation. J Trauma Acute Care Surg. 2013;75(5):824-9.

3. Hartyanszky I, Veres G, Huttl T, Moravcsik E, Kayser S, Daroczi L, et al. Osteosynthesis with plates for full sternal dehiscence (titanium sternal fixation system Synthes) -- first use in Hungary. Magyar sebeszet. 2009;62(2):67-70.

4. Sahin MA, Doganci S, Guler A. Repair of sternal dehiscence with titanium mesh plates: the sandwich technique. Thorac Cardiovasc Surg. 2011;59(1):49-50.

5. Schulz-Drost S, Mauerer A, Grupp S, Hennig FF, Blanke M. Surgical fixation of sternal fractures: locked plate fixation by low-profile titanium plates--surgical safety through depth limited drilling. Int Orthop. 2014;38(1):133-9.

6. Schulz-Drost S, Oppel P, Grupp S, Schmitt S, Carbon RT, Mauerer A, et al. Surgical fixation of sternal fractures: preoperative planning and a safe surgical technique using locked titanium plates and depth limited drilling. J Visualized Experiments. 2015;95:e52124.

7. Schulz-Drost S, Oppel P, Grupp S, Taylor D, Krinner S, Langenbach A, et al. The oblique fracture of the manubrium sterni caused by a seatbelt--a rare injury? Treatment options based on the experiences gained in a level I trauma Centre. Int Orthop. 2016;40(4):791-8.

8. Tasoglu I, Lafci G. Novel longitudinal plate-fixation technique after gross resection of the sternum. Tex Heart Inst J. 2012;39(2):215-7.

9. Voss B, Bauernschmitt R, Will A, Krane M, Kross R, Brockmann G, et al. Sternal reconstruction with titanium plates in complicated sternal dehiscence. Eur J Cardio-Thor Surg. 2008;34(1):139-45.

10. Huh J, Bakaeen F, Chu D, Wall MJ Jr. Transverse sternal plating in secondary sternal reconstruction. J Thorac Cardiovasc Surg. 2008;136(6):1476-80.

11. Moerenhout K, Rodrigus I, De Bock D, Vergauwen W, Stockman B. Titanium transverse plate fixation: a new solution for old sternal problems. Acta Chir Belg. 2009;109(3):371-5.

12. Nolasco-de la Rosa AL, Mosinoz-Montes R, Matehuala-Garcia J, RomanGuzman E, Quero-Sandoval F, Reyes-Miranda AL. Unstable thorax fixation with bioabsorbable plates and screws. Presentation of some cases. Cirugia y cirujanos. 2015;83(1):23-8.

13. Pouwels NSA, van Embden D, Hoogendoorn JM. Rib fixation for flail chest after resuscitation. Nederlands tijdschrift voor geneeskunde. 2018;162.

14. Qi FZ, Feng ZH, Zhang Y, Gu JY. The treatment of sternal wound infection by internal fixation of sternum with titanium plate after cardiac surgery. Zhonghua zheng xing Wai ke za zhi. 2013;29(1):8-11.

15. Zhao Y, Yang Y, Gao Z, Wu W, He W, Zhao T. Treatment of traumatic sternal fractures with titanium plate internal fixation: a retrospective study. J Cardiothorac Surg. 2017;12(1):22.

\section{Publisher's Note}

Springer Nature remains neutral with regard to jurisdictional claims in published maps and institutional affiliations. 